\title{
3D characterisation of porosity in an air plasma-sprayed thermal barrier coating and its effect on thermal conductivity
}

DOI:

10.1111/jace.15409

\section{Document Version}

Accepted author manuscript

Link to publication record in Manchester Research Explorer

Citation for published version (APA):

Zhang, X., Kulczyk-Malecka, J., Carr, J., Xiao, P., \& Withers, P. (2018). 3D characterisation of porosity in an air plasma-sprayed thermal barrier coating and its effect on thermal conductivity. Journal of the American Ceramic Society, 101(6), 2482-2492. https://doi.org/10.1111/jace.15409

\section{Published in:}

Journal of the American Ceramic Society

\section{Citing this paper}

Please note that where the full-text provided on Manchester Research Explorer is the Author Accepted Manuscript or Proof version this may differ from the final Published version. If citing, it is advised that you check and use the publisher's definitive version.

\section{General rights}

Copyright and moral rights for the publications made accessible in the Research Explorer are retained by the authors and/or other copyright owners and it is a condition of accessing publications that users recognise and abide by the legal requirements associated with these rights.

\section{Takedown policy}

If you believe that this document breaches copyright please refer to the University of Manchester's Takedown Procedures [http://man.ac.uk/04Y6Bo] or contact uml.scholarlycommunications@manchester.ac.uk providing relevant details, so we can investigate your claim.

\section{OPEN ACCESS}


Article type : Article

\section{Corresponding author mail}

\section{id:p.xiao@manchester.ac.uk}

3D characterisation of porosity in an air plasma-sprayed thermal barrier coating and its effect on thermal conductivity

Xun Zhang ${ }^{\text {a, b }}$, Justyna Kulczyk-Malecka ${ }^{\text {b, c }}$, James Carr ${ }^{\text {a, b }}$, Ping Xiao ${ }^{\text {b }}$, Philip J. Withers ${ }^{\text {a, b }}$

${ }^{a}$ Henry Moseley X-ray Imaging Facility, School of Materials, The University of Manchester, Manchester, M13 9PL, UK

${ }^{\mathrm{b}}$ School of Materials, The University of Manchester, Manchester, M13 9PL, U.K.

${ }^{\mathrm{c}}$ Surface Engineering Group, Manchester Metropolitan University, Manchester M1 5GD, UK

Abstract: Air plasma spray (APS) thermal barrier coatings (TBCs) contain pores, cracks and splat interfaces that are preferentially aligned normal to the heat flux direction. These significantly reduce (by as much as $50 \%$ ) the thermal conductivity over a fully dense coating. Here the microstructures of APS thermal barrier coatings (TBCs) have been characterised in 3D using X-ray micro-computed tomography $(\mu-\mathrm{CT})$. Pores larger than $2.8 \mu \mathrm{m}^{3}$ are resolved and their contribution to thermal conductivity reduction is evaluated using image-based microstructurally realistic numerical models. However, the models overestimate (by nearly $50 \%$ ) the measured thermal conductivity of the as-deposited TBC sample. It is shown that This article has been accepted for publication and undergone full peer review but has not been through the copyediting, typesetting, pagination and proofreading process, which may lead to differences between this version and the Version of Record. Please cite this article as doi: 10.1111/jace. 15409

This article is protected by copyright. All rights reserved. 
this discrepancy is due to very fine (micron and sub-micron) cracks which readily sinter after short term exposure to temperatures representative of TBC operating conditions causing the measured thermal conductivity to rise to within $15 \%$ of that predicted. This suggests that under the realistic service conditions, the 3D image-based models based on CT images provide a good indicator of the likely long-term TBC performance. Virtual experiments showed that for the retained pores, the larger pores which are flatter and more oriented in the plane of the APS splats, contribute disproportionately to the beneficial reduction in thermal conductivity. Our results demonstrate that X-ray imaging is a useful tool in establishing APS process conditions that gives rise to a beneficial distribution of such pores.

Key words: turbine blade; image-based modelling; high temperature; microstructure

\section{Introduction}

Thermal barrier coatings (TBCs) are widely used to provide thermal insulation and, in combination with a bond coat, oxidation resistance for metallic turbine blades [1]. The most commonly used material for TBC applications is yttria stabilised zirconia (YSZ) which has a low thermal conductivity $(\sim 2.5 \mathrm{~W} /(\mathrm{m} \cdot \mathrm{K})[2])$. On top of this, the presence of pores have been found to further enhance the insulating performance of the coating [1].

Among the many techniques to deposit TBCs, air plasma spray (APS) has been widely used due to its relatively low cost and versatility [1]. During plasma spraying, the ceramic (YSZ) particles are melted and ejected towards the target as droplets. Upon impinging on the surface of the component, these droplets solidify rapidly and form splats [3]. Consequently, APS TBCs have a splat-based microstructure with pores trapped in between the splats. In addition, the rapid solidification of the splat may induce cracking within the splat due to the quenching stress [4] while globular pores may arise around the entrained unmelted particles [5, 6]. As a 
result, the overall porosity of APS TBCs typically lie within $15 \% \sim 25 \%$ [1]. Crucially, the plasma spray process produces pores, cracks and splat interfaces that are preferentially aligned perpendicular to the heat flux direction further enhancing the insulating effect. As a result, practical APS TBCs can have a thermal conductivity just $40 \%$ of the bulk conductivity [2]. It is estimated that at $1500 \mathrm{~K}$, contribution from radiative heat transfer is around $0.05 \sim 0.1 \mathrm{~W} /(\mathrm{m} \cdot \mathrm{K})$, taking up less than $10 \%$ of the overall effective thermal conductivity [7]. Therefore, even at a high operation temperature $\left(>1300{ }^{\circ} \mathrm{C}\right)[1]$, thermal conduction, which is sensitive to the porosity within the coating, is still the dominant mechanism of heat transfer through the TBCs.

The correlation between porous structures and their effective thermal conductivity has been studied both analytically and experimentally [2, 4, 8-13]. Specifically for APS TBCs, their highly complex and anisotropic microstructures have made the microstructure-conductivity relationship difficult to determine [13]. This requires a comprehensive three dimensional (3D) description of the TBC microstructure. Kulkarni et al. [4] have volume averaged defect properties in TBCs using anisotropic multiple small angle neutron scattering (MSANS). Deshpande et al [14] used 2D image analysis to characterise the pores within the coatings. The validity of this image-based technique was authenticated by volume averaged SANS data. To correlate the microstructural features with the coating's conductivity, predictive FE models have been proposed based on the volumetrically averaged microstructural information determined from MSANS [4] as well as micrographs of the coatings $[2,15]$. In a follow-up study, Chi et al. [13] have probed the thermal conductivity-porosity relationship for various coatings at both ambient and elevated temperatures. Their results suggest that closely-spaced interfaces in the coatings can have a strong effect on their effective thermal conductivity although such interfaces only take up a small fraction of the total porosity. The significant 
and rapid increase in thermal conductivity upon thermal exposure has been ascribed to the closure of these closely spaced interfaces [2, 13].

The 3D nature of the heat transfer pathways in APS TBCs requires not only volumetrically averaged microstructural information, but also knowledge of the spatial distribution of the pores. Recent progress in X-ray computed tomography (CT) has made possible the detailed 3D quantification of porous microstructures [16]. Indeed, the subsurface microstructure of APS TBCs has recently been studied with micrometer resolution using lab-based X-ray microscopes $[17,18]$.

The aim of this paper is first to investigate whether 3D X-ray $\mu$-CT images are sufficient to predict the thermal conductivity performance of APS TBCs using image based numerical models. The second step, once validated, is to use this image based modelling approach to better understand the process by which the thermal conductivity of a TBC increases upon short term thermal exposure and to better understand how the size, distribution, morphology and orientation of pores and cracks contribute to the thermal conductivity. This information will help to optimise the fabrication of APS TBCs to gain greatest advantage from the porosity thus introduced.

\section{Experimental methods}

\subsection{Coating deposition}

Porous 8 wt.\% YSZ coatings having a thickness of $\sim 450 \mu \mathrm{m}$ were deposited by APS onto a Hastelloy ${ }^{\circledR} \mathrm{X}$ button having a diameter of $25.4 \mathrm{~mm}$. The thickness of the button was $\sim 6.4$ mm. The button surface was first grit blasted using alumina grit 60 size. Prior to YSZ deposition, a NiCoCrAlY (AMPERIT ${ }^{\circledR} 410$ ) overlay bond coat was applied to the substrate, 
also by APS, to a thickness of $~ 150 \mu \mathrm{m}$ using a Sulzer Metco Triplex Plasma Spray Guns. Finally, the YSZ topcoat was sprayed using a Sulzer Metco Triplex Pro gun in Forschungszentrum Jülich (IEK-1). A standard plasma gas composition of 46 standard liters per minute (slpm) Ar and 4 slpm He was used [19] with a current of $420 \mathrm{~A}$ and a spraying distance of $120 \mathrm{~mm}$.

\subsection{Thermal conductivity measurement}

The effective thermal conductivity (K) of the APS TBC was determined at room temperature by laser flash analysis [20]. In this analysis, a disk sample is heated on one side using an unfocused laser pulse. In the meantime, the temperature on the other side of the sample is recorded. The thermal diffusivity $(\alpha)$ along the thickness direction of the sample can be calculated based on the temperature evolution profile. According to Parker et al. [20], the thermal diffusivity of the sample at temperature $\mathrm{T}$ can be calculated using the time for the temperature to reach half of the recorded maximum $\left(\mathrm{t}_{1 / 2}\right)$ :

$$
\alpha(T)=\frac{1.38 d^{2}}{\pi^{2} t_{1 / 2}(T)}
$$

where $d$ is the thickness of the sample. However, Eq. 1 only holds for an infinitesimal pulse width. This is usually corrected for after measurement using the Cape-Lehman model [21]. Consequently, the thermal conductivity of the sample can be estimated through the relation:

$$
\mathrm{K}(\mathrm{T})=\alpha(\mathrm{T}) \cdot \rho(\mathrm{T}) \cdot \mathrm{C}_{\mathrm{p}}(\mathrm{T})
$$

where $\rho(T)$ and $C_{p}(T)$ are the density and specific heat of the sample at T respectively. In this study, laser flash analysis was conducted on free-standing YSZ coating samples using a Netzsch LFA 427 Laser Flash Apparatus. A ring-shaped trench with a diameter of $\sim 14 \mathrm{~mm}$ was made on the coating with a diamond coated core hole saw. The free-standing disk YSZ coating was obtained by immersing the button in hydrochloric acid to remove the substrate 
and bond coat. In this way, the thermal conductivity in the through-thickness direction (parallel to the spray direction) was measured.

The effective thermal conductivity was first measured for the coating in the as-deposited state. Afterwards, the sample was sintered at $1100{ }^{\circ} \mathrm{C}$ under an $\mathrm{Ar}$ atmosphere using the laser flash apparatus for $10 \mathrm{~h}$. The effective thermal conductivity of the sintered sample was measured after the sample returned to ambient temperature. Prior to measurement, the sample surface was coated with a thin layer of graphite to improve the laser absorption. Due to the relatively small sample thickness $(\sim 450 \mu \mathrm{m})$, the heat diffusion time can be comparable to the pulse time. Therefore, the smallest pulse width $(0.3 \mathrm{~ms}$ in this case $)$ has been used together with pulse correction based on the improved Cape-Lehman model [22]. Five measurements have been performed on one sample for consistency. The density and specific heat of the sample were determined using the Archimedes' method and differential scanning calorimetry (DSC) respectively.

\subsection{Microstructural characterisation}

Scanning electron microscopy (SEM) was employed to examine the pores inside the sample. The sample was first mounted in resin at room temperature. A cross-section was made through the coating and substrate using a $\mathrm{SiC}$ abrasive cutting blade. This was followed by progressive grinding using $\mathrm{SiC}$ grinding paper from 400 to 1200 grit at 200 interval. Finally, the cross-section was polished to a $0.25 \mu \mathrm{m}$ finish using successively finer diamonds $(6 \mu \mathrm{m}, 1$ $\mu \mathrm{m}$ and $0.25 \mu \mathrm{m})$.

This article is protected by copyright. All rights reserved. 
$\mathrm{X}$-ray $\mu$-CT was used to image the pore structure in 3D inside the coatings. The sample for $\mu-$ CT was cut from the same button from which the free-standing YSZ disk had been removed. A thin substrate-bondcoat-TBC slice $(600 \sim 800 \mu \mathrm{m})$ parallel to the thickness direction of the button was first cut out. In order to achieve sufficient X-ray transmission, the substrate was thinned using $\mathrm{SiC}$ grinding paper to a thickness similar to that of the coating $(\sim 500 \mu \mathrm{m})$. As a result, a rectangular prism sample was made whose base had a diagonal length of $\sim 1 \mathrm{~mm}$. This sample was scanned using a Zeiss ${ }^{\circledR}$ Versa 520 X-ray microscope in the Henry Moseley X-ray Imaging Facility. The X-ray tube was operated at $140 \mathrm{kV}$ producing polychromatic Xrays. A lead-glass X-ray filter was used to harden the X-ray beam and achieve $\sim 30 \%$ transmission for each projection. Each tomographic scan comprised 3201 projections equally spaced over a rotation angle of $360^{\circ}$. A $10 \mathrm{X}$ optical lens was applied after the scintillator for magnification. A voxel size of $0.57 \mu \mathrm{m}$ on the reconstructed virtual slices was achieved by the combination of optical lens and geometric magnification. Tomographic reconstruction was based on the FDK (Feldkamp-Davis-Kress) algorithm [23] using the XMReconstructor software provided by Zeiss ${ }^{\circledR}$.

Image processing including filtering, segmentation and quantification was carried out using Avizo 9.0 software. A non-local means filter was first applied to the reconstructed virtual slices to reduce noise $[24,25]$. A local thresholding method (top hat) was used to segment the pores, which selects valleys by a series of morphological operations on the grey-scale image.

Details of this method can be found in [26].

This article is protected by copyright. All rights reserved. 
Quantitative analysis of the microstructure was achieved on the segmented 3D images. It was observed that the pores were essentially inter-connected. In order to quantify the morphology of the pores, each individual pore needed to be distinguished. This has been achieved using the 'Separate Object' module in Avizo [25]. This method is based on the watershed of the distance map of the binary image [27]. As a result, the connected pores were separated at their narrowest points and the volume, shape and orientation were quantified pore by pore [28]. The pores could then be categorised based on their 3D volumes as determined from image analysis.

\subsection{Image-based Models}

In order to quantify the effect of pores on the effective thermal conductivity of the coating, image-based modelling was conducted utilising the segmented 3D images of the YSZ topcoat. The Avizo XLab Thermo Pack [25] was used to simulate the heat flux through the porous TBC system.

Transient heat conduction in the YSZ solid in the TBC can be described using the partial differential equation:

$$
\rho C_{p} \frac{\partial T}{\partial t}-K_{Y S Z} \nabla^{2} T=0
$$

where $\rho$ is the density, $C_{p}$ is the specific heat, $K_{Y S Z}$ is the thermal conductivity and $T$ is the temperature of the bulk YSZ. The thermal conductivity of the fully-dense YSZ was taken as $\mathrm{K}_{\mathrm{Y} \mathrm{SZ}}=2.5 \mathrm{~W} /(\mathrm{m} \cdot \mathrm{K})[2]$. As the thermal conductivity of air $(\sim 0.026 \mathrm{~W} /(\mathrm{m} \cdot \mathrm{K})$ at room temperature [29]) is about 2 orders lower than that of YSZ, pores have been assumed to be heat insulators in the simulations. A steady state was assumed so that the transient heat conduction problem (Equation (3)) reduced to solving a time-invariant temperature field under the constraint of constant boundary temperatures as expressed in Equation (4).

This article is protected by copyright. All rights reserved. 


$$
\frac{\mathrm{Q}}{\mathrm{S}}=\mathrm{K}_{\mathrm{a}} \frac{\mathrm{T}_{\text {out }}-\mathrm{T}_{\text {in }}}{\mathrm{t}}
$$

where $\mathrm{Q}$ is the total heat flux through the input face, $\mathrm{S}$ is the area of the input surface, $\mathrm{T}_{\text {out }}$ and $\mathrm{T}_{\text {in }}$ are the imposed temperatures at the out and inner surface respectively, $t$ is the thickness of the region through which heat flows and $\mathrm{K}_{\mathrm{a}}$ is the apparent thermal conductivity of the porous topcoat in the coating's thickness direction.

A finite volume method has been used with each voxel serving as an isotropic cubic volume element [25]. Once discretized, the steady-state temperature field was found by solving the Fourier equation systems using a fully implicit method. A conjugate gradient iteration with an ILU preconditioner was performed until the relative decrease of norm of the residual was less than a pre-set criterion $\left(10^{-5}\right.$ in this study) [25].

Simulations were conducted using the 3D micrographs of the real coating sample (Figure 4). As has been pointed out in [2], the model domain needs to be large enough, and contain sufficient microstructural details, to represent the average features of the coating. On the other hand, a large model domain means a much higher computational cost. Considering the voxel size of the reconstructed virtual slice $(0.57 \mu \mathrm{m})$, a region of interest (ROI) with a size of $100 \times 100 \times 100 \mu \mathrm{m}^{3}$ contains around 5,400,000 volume elements. Therefore, a domain size check was first conducted by incrementally changing the size of the region of interest (ROI) for the simulation until the calculated thermal conductivity converged. Further increase in the domain had little benefits on the robustness of the calculated thermal conductivity, but would significantly increase the computational cost.

Figure 1 shows the predicted thermal conductivity values as a function of the size of the ROI picked randomly at 3 positions within the sample. All the ROIs span the full coating thickness. Figure 1 suggests that a ROI size of at least $200 \mu \mathrm{m}$ is necessary to produce a representative volumetrically averaged thermal conductivity value. The fluctuations observed 
at a small ROI size are mainly due to the uneven distribution of the microstructural constituents e.g. pore clusters or local pore-free zones larger than the ROI. Therefore, all simulations have been run with a ROI size of around $200 \times 200 \times 200 \mu \mathrm{m}^{3}$.

\section{Results}

\subsection{Microstructural features in the as-deposited sample}

To validate the $\mu$-CT results, the polished cross-section of the as-deposited coating was imaged using scanning electron microscope (SEM) and shown in Figure 2 (b) alongside a virtual $\mu$-CT cross-section. The three distinct layers within the APS TBC system are clearly distinguished. Pores are observed in the topcoat and bond coat. Both globular and interlamellar cracks within the topcoat and bond coat are observed on the virtual $\mu$-CT crosssection. In the bond coat, inter-lamellar cracks predominate whereas in the topcoat the globular pores are more pronounced. The SEM image suggests that in addition to the wide inter-lamellar cracks (yellow rectangle in Figure 2(b)), fine (sub-micron opening) interlamellar cracks are present (e.g. the insert in Figure 2(b)). Their fine scale means that are not resolved in the $\mu$-CT cross-section. Moreover, although some of the inter-splat cracks can be detected in the virtual $\mu$-CT cross-section, they have not been clearly resolved. Instead, they appear as blurred and greyish phases in the slice due to the limited resolution and partial volume effect [30].

\subsection{Quantification of defects in the YSZ topcoat}

In order to quantify the different types of defects (i.e. globular pores and inter-lamellar cracks), they must first be segmented from the CT volume images as shown in Figure 3.

The top-hat method gives a more or less satisfactory segmentation result (see Figure 3(c)) for the pores in the YSZ topcoat. Comparing Figure 3(b) and 3(c), it can be seen that the large 
and globular pores in the YSZ are precisely labelled. However, when it comes to the fine and planar inter-lamellar cracks (yellow arrow in Figure 3 (a) and (b)), segmentation proves difficult. In some situations, the cracks could not be segmented from the YSZ as their widths are much smaller than the voxel size of the CT image (e.g. insert in Figure 2(b)). There are other situations where over-segmentation occurred when the cracks were detected and segmented whereas their opening has been less than the size of one voxel [31]. In spite of these difficulties, the porosity of the YSZ topcoat has been determined from the 3D images as $16.1 \pm 0.7 \%$. By comparison, image analysis on the cross-section SEM micrographs yield a value of $17.6 \pm 1.3 \%$. The discrepancy is primarily due to the fine inter-lamella cracks not being resolved by X-ray $\mu$-CT. Moreover, sample preparation i.e. grinding and polishing may have introduced damage to the cross-sections for SEM investigation, leading to a higher porosity level.

In addition to obtaining the total porosity, the pores captured by X-ray $\mu$-CT have been categorised based on their 3D volumes. Figure 4 shows 3D images of the pores on each volume range and the contribution of each type of pores to the total porosity by the cumulative porosity profile.

Figure 4 (b-g) show a transition with increasing size in the morphology of the pores from randomly distributed spheres to more torturous and oriented clusters. In addition, it can be observed that the larger pores (i.e. $>10000 \mu \mathrm{m}^{3}$ ), which constitute the majority of the porosity detected (according to Figure 4 (a)), have complex surface morphologies. In order to quantitatively describe the shape of the pores, their sphericity $(\Phi)$ has been determined from the 3D images. The sphericity of a 3D particle is defined as: 


$$
\Phi=\frac{\pi^{1 / 3}(6 \mathrm{~V})^{2 / 3}}{\mathrm{~A}}
$$

where $\mathrm{V}$ and $\mathrm{A}$ are the volume and surface area of the particle respectively where a sphere gives $\Phi=1$.

Figure 5 plots the sphericity and the alignment the pores as a function of their size. Figure 5 (a) confirms the observation in Figure 4 that the pores become less spherical as their sizes increase. The sphericity of the pores is seen to decrease linearly with the logarithm of their volume. Likewise the pores become more aligned with the plane of the coating (plane of the splats) as their size increases. The dependence of both the pores' shape and orientation on their volume has been a result of the splat-based microstructure. As noted previously [32], the larger pores tend to be those arising from air trapped in between the splats: as a result they tend to follow the shape and orientation of the splats.

\subsection{Thermal conductivity}

The measured thermal conductivity has been compared with the model predictions and the results are summarised in Figure 6.

The effective through-thickness thermal conductivity measured on the as-deposited freestanding coating is $1.20 \pm 0.12 \mathrm{~W} /(\mathrm{m} \cdot \mathrm{K})(48 \pm 5 \%$ of the bulk value $)$. By comparison, the image based model predicts a conductivity of $1.76 \pm 0.05 \mathrm{~W} /(\mathrm{m} \cdot \mathrm{K})(30 \pm 1 \%$ reduction from the bulk value). This suggests that the pores detected by X-ray $\mu$-CT account for only $\sim 60 \%$ of the total reduction in thermal conductivity. The splat boundaries and fine inter-lamella cracks (on the scale of sub-micrometre), which have not been resolved in the $\mu$-CT slices are probably the main reason for the difference between the measured and predicted thermal conductivity [2] and this is investigated below. 
It should be noted that, effective as they are in reducing the thermal conductivity of the asdeposited coating, the splat interfaces and fine inter-splat cracks are prone to sintering considering the service temperature of the TBCs. This may explain why it has been reported that the thermal conductivity of an as-deposited TBC increases significantly (by as much as $46 \%)$ and rapidly (after $10 \mathrm{~h}$ ) upon thermal exposure $\left(1100{ }^{\circ} \mathrm{C}\right)$ due to the closure of closely spaced splat interfaces despite little change in the total volume fraction of porosity [13].

To investigate the effect of sintering on the thermal conductivity, we have sintered the freestanding TBC sample at $1100{ }^{\circ} \mathrm{C}$ for $10 \mathrm{~h}$. After sintering the thermal conductivity of the sintered sample has increased (from $1.20 \pm 0.12 \mathrm{~W} /(\mathrm{m} \cdot \mathrm{K}$ ) to $1.55 \pm 0.18 \mathrm{~W} /(\mathrm{m} \cdot \mathrm{K})$ ), which is close to the predictions from the $\mu$-CT image-based simulations of the as-deposited sample.

\section{Discussion}

\subsection{Investigation into the role of the fine cracks}

It is reported above that the 3D X-ray $\mu$-CT image-based model overestimates (by nearly 50 $\%$ ) the thermal conductivity of the as-deposited TBC sample and it is postulated that this is due to very fine cracks. The SEM image in Figure 2(b) confirms the existence of cracks both on the micron and sub-micron scales. Other workers have also reported cracks/pores in APS TBCs across a wide range of scales (from $\sim 100 \mu \mathrm{m}$ down to nanometers) [33-35]. Such fine cracks cannot be clearly resolved in the $\mu$-CT virtual slices even though there is some contrast suggesting the presence of such features. Under the current scanning setup, a voxel size of $0.57 \mu \mathrm{m}$ has been employed, which alongside image filtering to remove noise in the images and facilitate segmentation, leads to the loss of detailed features (e.g. interfaces in Figure 3(a)). As a result, only pores and cracks with a volume larger than 15 voxels were considered as defects (pores and cracks). This corresponds to a volume of around $2.8 \mu \mathrm{m}^{3}$.

In order to establish whether the fine defects and interfaces could explain the $~ 50 \%$ 
overestimation in the thermal conductivity of the as-deposited TBC sample, we have employed the contact-zone model as defined in [36] to quantify the contribution to the thermal conductivity reduction from these features. The idea being to treat the inter-splat gaps as a semi-insulating medium with a degraded thermal conductivity value. In this case, highresolution SEM micrographs (pixel size $\approx 0.1 \mu \mathrm{m}$ ) were used as input for the image-based models. Features smaller than the X-ray $\mu$-CT resolution limit i.e. inter-splat gaps thinner than $1 \mu \mathrm{m}$ and pores smaller than $\sim 1.7 \mu \mathrm{m}$ (this corresponds to a sphere smaller than $2.8 \mu \mathrm{m}^{3}$ in 3D) were taken as contact zones to which a degraded thermal conductivity has been assigned (Figure 7).

As explained in [36], it is not possible to determine the effective thermal conductivity of the contact zones experimentally. Instead, a series of reduced thermal conductivity values have been used for the contact zones. The calculated effective thermal conductivity is plotted against that of the contact zone in Figure 8. When the contact zones are fully insulating $\left(\mathrm{K}_{\mathrm{CZ}} / \mathrm{K}_{\mathrm{Bulk}}<10^{-4}\right)$, the effective thermal conductivity of the sample is only $0.29 \mathrm{~W} /(\mathrm{m} \cdot \mathrm{K})$, which is less than $25 \%$ of the measured value. In fact, the simulated thermal conductivity matches the experiment measurements when $\mathrm{K}_{\mathrm{CZ}}$ is about half of $\mathrm{K}_{\mathrm{Bulk}}$. This could be because specimen preparation introduces some of the fine cracks seen in the micrograph, or that the inter-splat gaps are only $50 \%$ effective in providing insulation in the real TBCs possibly because they are not fully open.

\subsection{Investigation of the effect of sintering on microstructure}

It was postulated above that the increase in the measured thermal conductivity after sintering is due to the closure of closely spaced splat interfaces. To investigate this further the same ROI on the sample was re-imaged by $\mathrm{X}$-ray $\mu$-CT after sintering at $1100{ }^{\circ} \mathrm{C}$ for $10 \mathrm{~h}$ in air. A pair of corresponding virtual cross-sections are shown in Figure 9. 
As evident in Figure 9, upon sintering a significant thermally grown oxide (TGO) has developed at the topcoat/bond coat interface. In addition cracks have initiated at some locations within the topcoat close to the topcoat/bond coat interface. However, these changes have little effect on the thermal conductivity measurements as these were made on the freestanding as-sintered coating. Other than these, no detectable changes could be observed on the virtual cross-sections of the YSZ topcoat. The same image processing routine was used on the X-ray images of the as-sintered sample. Figure 9 (c) and (d) show an example of one large pore $\left(>2.8 \mu \mathrm{m}^{3}\right)$ inside the sample before and after sintering. Both the 2D slice and 3D image suggest that no detectable changes can be identified from the X-ray images of the sampel after the sintering treatment. Based on this, the quantification on the cumulative porosity, pore morphology and orientation (as shown in Figure 4-5) will remain unchanged after sintering. Indeed, the porosity determined from the X-ray images of the as-sintered sample is $16.0 \pm 0.5 \%$.

The cross-sectional SEM images (Figure 9 (e) and (f)) also suggest that the large pores (> 10 $\mu \mathrm{m}$ in diameter) have changed little during sintering. However, the thin inter-splat cracks (inserts in Figure 9 (e) and (f)) seem to have narrowed after sintering due to diffusion and grain growth across the inter-splat boundaries at sintering temperature $\left(1100{ }^{\circ} \mathrm{C}\right.$ in this study) [37].

In view of the fact that the thermal conductivity predicted by the X-ray CT image-based model $(1.74 \pm 0.03 \mathrm{~W} /(\mathrm{m} \cdot \mathrm{K})$ for the as-sintered sample) now comes into close agreement with the measured as-sintered conductivity (model prediction is about $12 \%$ higher than the measured value), this provides conclusie evidence that it is the fine scale cracks that are responsible for the increase in thermal conductivity during the early stages of thermal 
exposure. Further it validates that X-ray CT imaging is able to capture the larger scale pores and cracks that are reponsible for the long term thermal conductivity of the coating and that image based modelling can reliably predict long term thermal conductivity.

\subsection{The contribution to the thermal conductivity of different types of pores}

Given that the image-based model is in close accordance with the as-sintered (i.e. likely inservice) thermal conductivity of the coating, it can be used to assess the contribution to the conductivity of the different types of pores found in the coating. The contribution to the total porosity and reduction in thermal conductivity for each type of pore (see Figure 4) has been plotted in Figure 10. It is evident that pores having volumes in the range 20,000 100,000 $\mu \mathrm{m}^{3}$ (size 4 in Figure 10) constitute most of the pore space and contribute most to the reduction in conductivity over bulk YSZ. Although the relatively small pores $\left(<20000 \mu \mathrm{m}^{3}\right.$ i.e. size 1,2 and 3 in Figure 10) are large in number, as visualised in Figure 4, they account for less than $25 \%$ of the total porosity and $5.3 \%$ of the reduction in thermal conductivity. It is noteworthy that although the total volume of pores lager than $200,000 \mu \mathrm{m}^{3}$ (size 6 in Figure 10) is less than that of pores on the range of $5000 \sim 20000 \mu \mathrm{m}^{3}$ (size 3 in Figure 10), they contribute more to the reduction in thermal conductivity.

In order to compare the effectiveness of each type or pore in reducing the conductivity, the volume normalised conductivity reduction has been plotted in Figure 11. Figure 11 suggests that the effectiveness of pores in reducing the conductivity is linearly related to their volume. The reduction per unit volume of a $250,000 \mu \mathrm{m}^{3}$ pore is more than twice as effective as a $1,500 \mu \mathrm{m}^{3}$ pore. A numerical study looking at different sizes and shapes of pores confirms that this is probably because the larger pores are flatter and tend to lie within the plane of the coating (perpendicular to the heat flux).

This article is protected by copyright. All rights reserved. 


\section{Conclusions}

In this study, the pore microstructure-conductivity relationship has been explored for a TBC deposited by APS. Detailed microstructural characterisation has been carried out by $\mu$-CT and scanning electron microscopy in the as-deposited condition, as well as after sintering at temperatures representative of in-service conditions. Considering that thermal conduction through the YSZ solid is still the dominant heat transfer mechanism even at service temperature of the TBCs, 3D image-based microstructurally realistic models have been developed to explore the effect of the porosity on the reduction in conductivity of the coating. The following concluding remarks can be drawn:

1. The effective thermal conductivity of the as-deposited TBC topcoat can be as low as $50 \%$ of a fully dense YSZ due to the existence of pores and splat interfaces. Among these, X-ray $\mu$-CT was used to image the pores larger than $2.8 \mu \mathrm{m}^{3}$ in volume. Comparison of the X-ray virtual slices taken before and after sintering suggests that the X-ray images are robust in resolving such large defects in the APS TBC. X-ray $\mu$ CT image based modelling suggested these contribute $\sim 60 \%$ of the total reduction in thermal conductivity.

2. It was shown that fine cracks, mostly inter-splat cracks identified in SEM micrographs, are more than sufficient to explain the remaining reduction in conductivity. Indeed a good match between experiment and model is reached when the conductivity of the inter-spat gap is about half of the bulk value for the asdeposited sample.

3. The narrowing of overlapping splats via diffusion and grain growth across inter-splat boundaries during sintering treatment causes the measured thermal conductivity of the coating to rise from $1.20 \pm 0.12 \mathrm{~W} /(\mathrm{m} \cdot \mathrm{K})$ to $1.55 \pm 0.18 \mathrm{~W} /(\mathrm{m} \cdot \mathrm{K})$. At the same time the coarser defects (i.e. defects larger than $2.8 \mu \mathrm{m}^{3}$ ) are found to be stable during this 
sintering treatment. As a result, the measured conductivity of the as-sintered coating comes to within $15 \%$ of that predicted on the basis of the coarser defects. This implies that the long-term thermal conductivity of an APS TBC topcoat can be predicted by $\mathrm{X}$-ray $\mu$-CT image-based models developed from an as-deposited sample.

4. The shapes of the pores within the YSZ topcoat are strongly related to their size. Small pores are roughly spherical while large pores are more tortuous and much flatter and tend to lie within the plane of the splats. As a result the larger pores are more effective in reducing the thermal conductivity.

The fact that the X-ray $\mu$-CT can detect the pores that are stable under realistic in-service temperatures suggests that $3 \mathrm{D}$ x-ray imaging is a good way of helping to optimise APS process control in terms of the optimisation of retained porosity for improved thermal conductivity.

\section{Acknowledgements}

The authors acknowledge the provision of beam time at Henry Moseley Manchester X-ray Imaging Facility (HMXIF) at the University of Manchester, UK, established with funding from EPSRC through grants EP/F007906, EP/I02249X and EP/F028431 and HEFCE funding of the Multiscale Characterisation Facility. PJW is grateful for a European Research Council for funding COREL-CT under grant No 695638. The authors acknowledge Prof. Robert Vaßen and Dr. Denise Koch for providing the APS TBC samples.

This article is protected by copyright. All rights reserved. 


\section{References}

1. Padture NP, Gell M, Jordan EH. Materials science - Thermal barrier coatings for gasturbine engine applications. Science. 2002 Apr 12;296(5566):280-4.

2. Wang Z, Kulkarni A, Deshpande S, Nakamura T, Herman H. Effects of pores and interfaces on effective properties of plasma sprayed zirconia coatings. Acta Mater. 2003 Oct 20;51(18):5319-34.

3. Sampath S, Schulz U, Jarligo MO, Kuroda S. Processing science of advanced thermal-barrier systems. Mrs Bull. 2012 Oct;37(10):903-10.

4. Kulkarni A, Wang Z, Nakamura T, Sampath S, Goland A, Herman H, et al. Comprehensive microstructural characterization and predictive property modeling of plasmasprayed zirconia coatings. Acta Mater. 2003 May 23;51(9):2457-75.

5. Mcpherson R. A Review of Microstructure and Properties of Plasma Sprayed Ceramic Coatings. Surf Coat Tech. 1989 Dec 1;39(1-3):173-81.

6. Kulkarni A, Vaidya A, Goland A, Sampath S, Herman H. Processing effects on porosity-property correlations in plasma sprayed yttria-stabilized zirconia coatings. Materials Science and Engineering a-Structural Materials Properties Microstructure and Processing. 2003 Oct 25;359(1-2):100-11.

7. Golosnoy IO, Cipitria A, Clyne TW. Heat Transfer Through Plasma-Sprayed Thermal Barrier Coatings in Gas Turbines: A Review of Recent Work. Journal of Thermal Spray Technology. 2009 Dec;18(5-6):809-21.

8. Cernuschi F, Bison P, Moscatelli A. Microstructural characterization of porous thermal barrier coatings by laser flash technique. Acta Mater. 2009 Jul;57(12):3460-71.

9. Cernuschi F, Ahmaniemi S, Vuoristo P, Mantyla T. Modelling of thermal conductivity of porous materials: application to thick thermal barrier coatings. J Eur Ceram Soc. 2004 Aug;24(9):2657-67.

This article is protected by copyright. All rights reserved. 
10. Nait-Ali B, Haberko K, Vesteghem H, Absi J, Smith DS. Thermal conductivity of highly porous zirconia. J Eur Ceram Soc. 2006;26(16):3567-74.

11. Ahmaniemi S, Vuoristo P, Mantyla T, Cernuschi F, Lorenzoni L. Modified thick thermal barrier coatings: Thermophysical characterization. J Eur Ceram Soc. 2004 Aug;24(9):2669-79.

12. Zhu DM, Miller RA. Thermal conductivity and elastic modulus evolution of thermal barrier coatings under high heat flux conditions. Journal of Thermal Spray Technology. 2000 Jun;9(2):175-80.

13. Chi WG, Sampath S, Wang H. Microstructure-thermal conductivity relationships for plasma-sprayed yttria-stabilized zirconia coatings. Journal of the American Ceramic Society. 2008 Aug;91(8):2636-45.

14. Deshpande S, Kulkarni A, Sampath S, Herman H. Application of image analysis for characterization of porosity in thermal spray coatings and correlation with small angle neutron scattering. Surf Coat Tech. 2004 Oct 1;187(1):6-16.

15. Arai M, Ochiai H, Suidzu T. A novel low-thermal-conductivity plasma-sprayed thermal barrier coating controlled by large pores. Surf Coat Tech. 2016 Jan 15;285:120-7.

16. Maire E, Withers PJ. Quantitative X-ray tomography. International Materials Reviews. 2014 Jan;59(1):1-43.

17. Zhao Y, Shinmi A, Zhao X, Withers PJ, Van Boxel S, Markocsan N, et al. Investigation of interfacial properties of atmospheric plasma sprayed thermal barrier coatings with four-point bending and computed tomography technique. Surf Coat Tech. 2012 Jul $15 ; 206(23): 4922-9$.

18. Ahmadian S, Browning A, Jordan EH. Three-dimensional X-ray micro-computed tomography of cracks in a furnace cycled air plasma sprayed thermal barrier coating. Scripta Materialia. 2015 Mar 1;97:13-6.

This article is protected by copyright. All rights reserved. 
19. Mauer G, Du LN, Vassen R. Atmospheric Plasma Spraying of Single Phase Lanthanum Zirconate Thermal Barrier Coatings with Optimized Porosity. Coatings. 2016 Dec;6(4).

20. Parker WJ, Jenkins RJ, Abbott GL, Butler CP. Flash Method of Determining Thermal Diffusivity, Heat Capacity, and Thermal Conductivity. Journal of Applied Physics. 1961;32(9):1679-\&.

21. Cape JA, Lehman GW. Temperature and Finite Pulse-Time Effects in Flash Method for Measuring Thermal Diffusivity. Journal of Applied Physics. 1963;34(7):1909-\&.

22. Blumm J, Opfermann J. Improvement of the mathematical modeling of flash measurements. High Temperatures-High Pressures. 2002;34(5):515-21.

23. Feldkamp LA, Davis LC, Kress JW. Practical cone-beam algorithm. Journal of the Optical Society of America a-Optics Image Science and Vision. 1984 1984;1(6):612-9.

24. Liu YL, Wang J, Chen X, Guo YW, Peng QS. A robust and fast non-local means algorithm for image denoising. Journal of Computer Science and Technology. 2008 Mar;23(2):270-9.

25. Avizo User Guide,Visualization sciences group SAS. 2013.

26. Serra J. Introduction to Mathematical Morphology. Computer Vision Graphics and Image Processing. 1986 Sep;35(3):283-305.

27. Kimmel R, Kiryati N, Bruckstein AM. Sub-pixel distance maps and weighted distance transforms. Journal of Mathematical Imaging and Vision. 1996 Jun;6(2-3):223-33.

28. Brabant L, Vlassenbroeck J, De Witte Y, Cnudde V, Boone MN, Dewanckele J, et al. Three-Dimensional Analysis of High-Resolution X-Ray Computed Tomography Data with Morpho+. Microscopy and Microanalysis. 2011 Apr;17(2):252-63.

This article is protected by copyright. All rights reserved. 
29. Lima JAP, Marin E, da Silva MG, Sthel MS, Schramm DU, Cardoso SL, et al. Characterization of the thermal properties of gases using a thermal wave interferometer. Measurement Science and Technology. 2001 Nov;12(11):1949-55.

30. Erlandsson K, Buvat I, Pretorius PH, Thomas BA, Hutton BF. A review of partial volume correction techniques for emission tomography and their applications in neurology, cardiology and oncology. Physics in Medicine and Biology. 2012 Nov 7;57(21):R119-R59.

31. Withers PJ, Preuss M. Fatigue and Damage in Structural Materials Studied by X-Ray Tomography. Annual Review of Materials Research, Vol 42. 2012;42:81-103.

32. Mcpherson R. The Relationship between the Mechanism of Formation, Microstructure and Properties of Plasma-Sprayed Coatings. Thin Solid Films. 1981;83(3):297-310.

33. Funke C, Mailand JC, Siebert B, Vassen R, Stover D. Characterization of ZrO2-7 wt\% Y2O3 thermal barrier coatings with different porosities and FEM analysis of stress redistribution during thermal cycling of TBCs. Surf Coat Tech. 1997 Oct;94-5(1-3):106-11. 34. Vassen R, Cao XQ, Tietz F, Basu D, Stover D. Zirconates as new materials for thermal barrier coatings. Journal of the American Ceramic Society. 2000 Aug;83(8):2023-8.

35. Guo HB, Vassen R, Stover D. Atmospheric plasma sprayed thick thermal barrier coatings with high segmentation crack density. Surf Coat Tech. 2004 Sep;186(3):353-63.

36. Zivelonghi A. Thermomechanical behaviour of two heterogeneous tungsten materials via 2D and 3D image-based FEM. 2011.

37. Thompson JA, Clyne TW. The effect of heat treatment on the stiffness of zirconia top coats in plasma-sprayed TBCs. Acta Mater. 2001 May 25;49(9):1565-75.

This article is protected by copyright. All rights reserved. 


\section{Figure Captions}

Figure 1: Thermal conductivity as a function of the (square based) ROI size determined at three randomly picked positions. All ROI span the coating thickness.

Figure 2: Comparison a) a virtual $\mu$-CT cross-section and b) a destructive cross-section imaged by SEM (BSE) in the as-deposited condition.

Figure 3: A typical virtual cross-section a) before; b) after non-local means filtering and c) after segmentation. The filtering has helped remove noise in the image and differentiate the layers but also smeared out small features.

Figure 4: 3D images of typical pores categorised based on their 3D volume and contribution of each type of pores to the total porosity: a) cumulative porosity determined from segmented 3D X-ray image and 3D view of pores in the size range b) $0-500 \mu \mathrm{m}^{3}$; c) $500-5000 \mu \mathrm{m}^{3}$; d) $5000-20000 \mu \mathrm{m}^{3}$; e) $20000-100000 \mu \mathrm{m}^{3}$; f) $100000-200000 \mu \mathrm{m}^{3}$ and g) $>200000 \mu \mathrm{m}^{3}$

Figure 5: Shape and orientation of the pores as a function of their volume determined from the 3D images: a) sphericity and b) alignment of the pore's long axis with the normal to the coating. The horizontal error bar represents the scatter in pore size and the vertical one represents the scatter in sphericity and orientation of the pores with that range of size.

This article is protected by copyright. All rights reserved. 
Figure 6: Comparison of the measured reduction in effective through-thickness thermal conductivity (expressed as the $\%$ of the bulk conductivity) with model predictions. For the model predictions on the as-deposited sample, the contribution of each type of pores has been isolated and highlighted using the sample colour code shown in Figure 4.

Figure 7: a) High magnification SEM micrograph of the coating and b) the same image showing the segmented pores (blue) and contact zones (red).

Figure 8: Simulated TBC thermal conductivity as a function of the contact zone conductivity, $\mathrm{K}_{\mathrm{CZ}}$, normalised by that of bulk YSZ.

Figure 9: The same X-ray $\mu$-CT virtual cross-section viewed a) as-deposited and b) after sintering at $1100{ }^{\circ} \mathrm{C}$ for 10 ; one large pore inside the YSZ topcoat viewed in 3D c) asdeposited and d) after sintering along with SEM images e) as deposited and f) after sintering.

Figure 10: A comparison of the predicted contribution of each individual pore type to the total porosity and thermal conductivity reduction predicted by image-based simulations. The colour code for the columns are the same as in Figure 4 and Figure 6.

Figure 11: Volume averaged reduction in thermal conductivity for pores with different volume.

This article is protected by copyright. All rights reserved. 


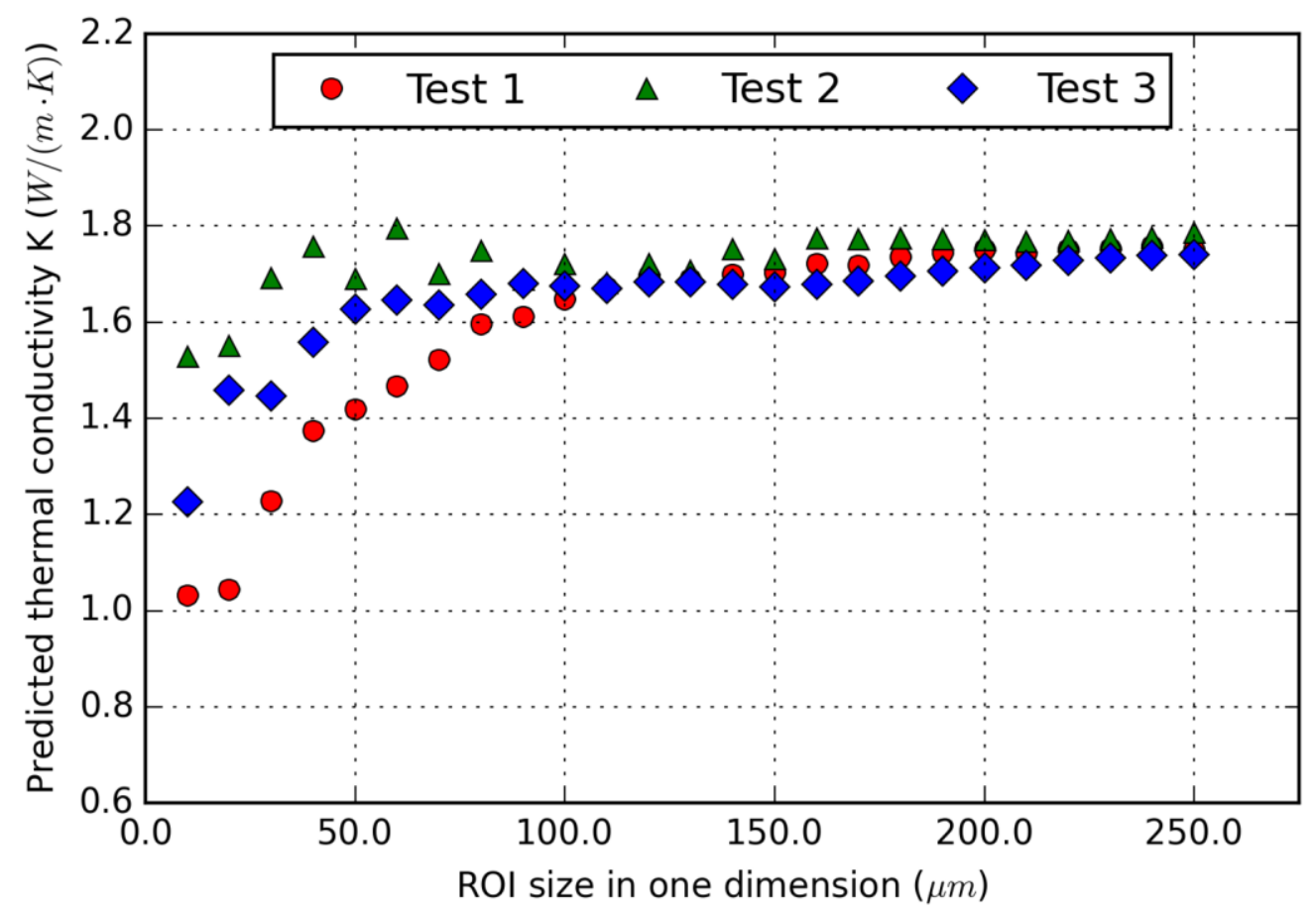

This article is protected by copyright. All rights reserved. 


\section{(a)}

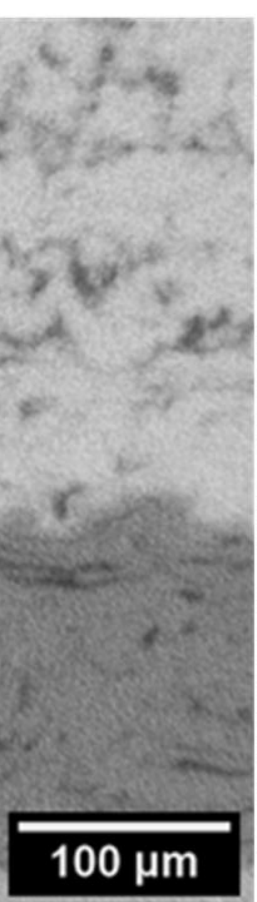

(b) $7 \mathrm{~h}$
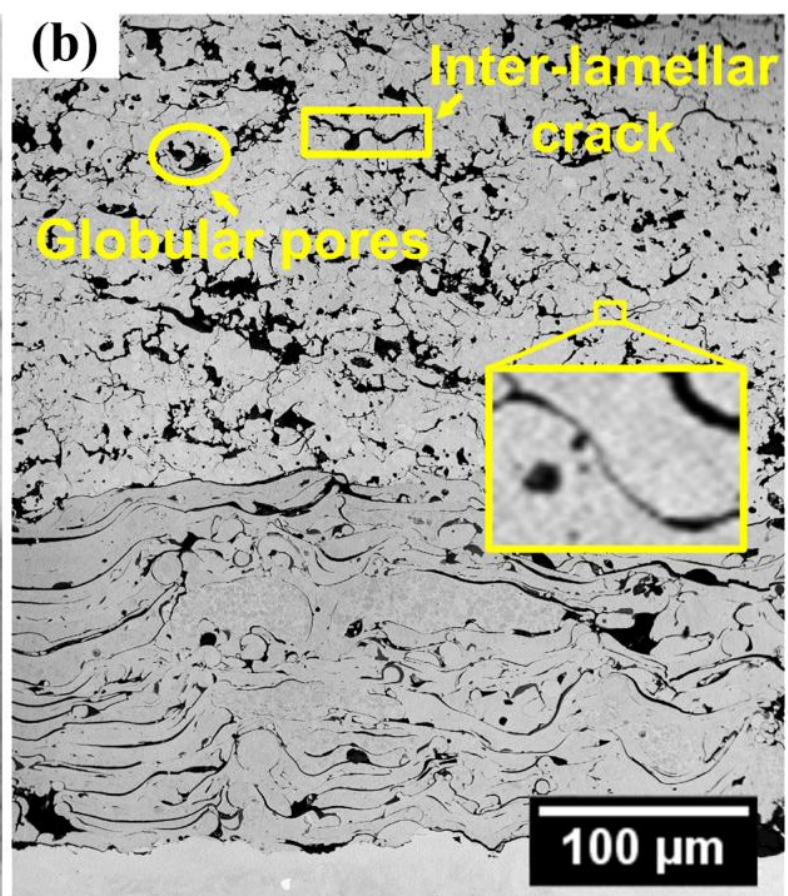

This article is protected by copyright. All rights reserved. 


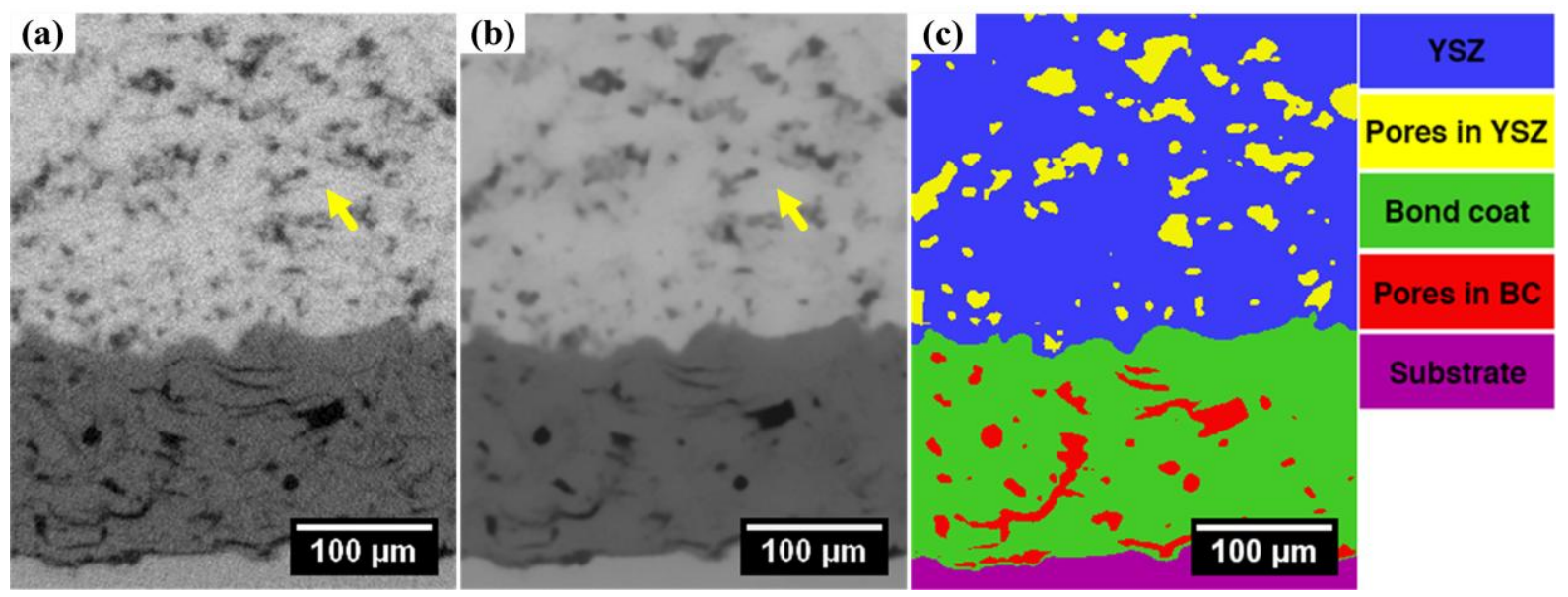

This article is protected by copyright. All rights reserved. 
(a)

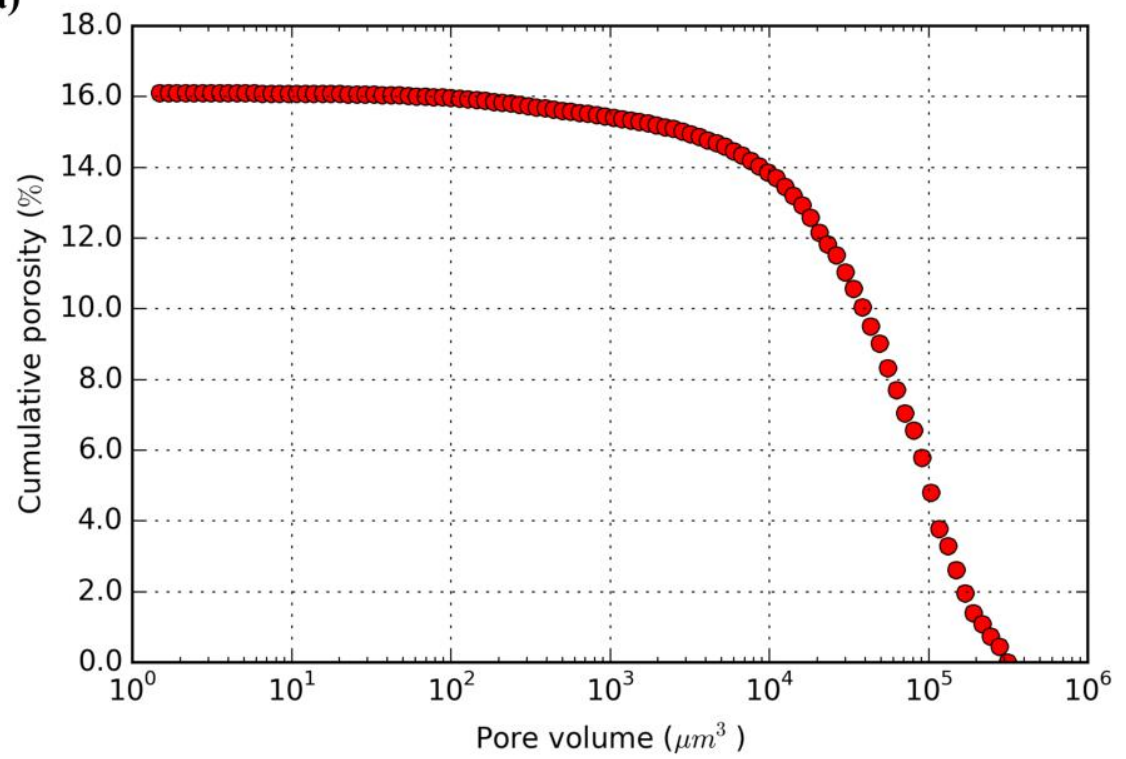

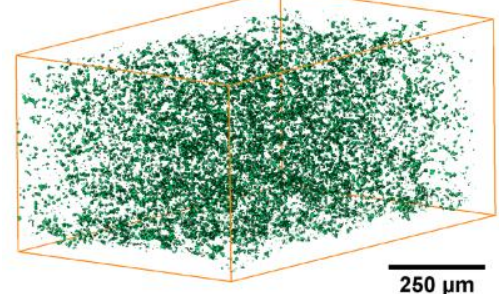

(b)

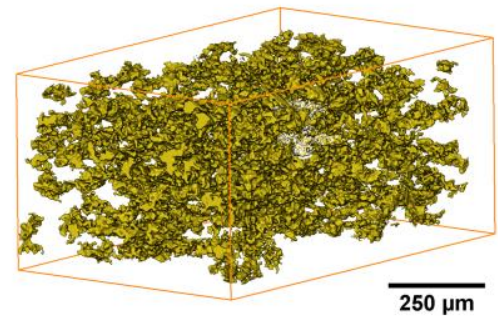

(e)

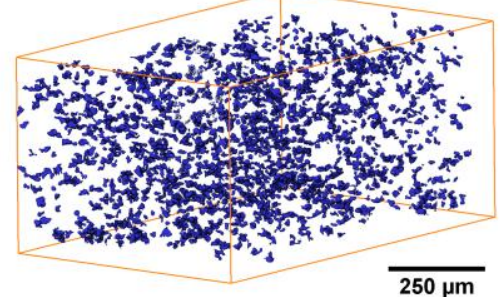

(c)

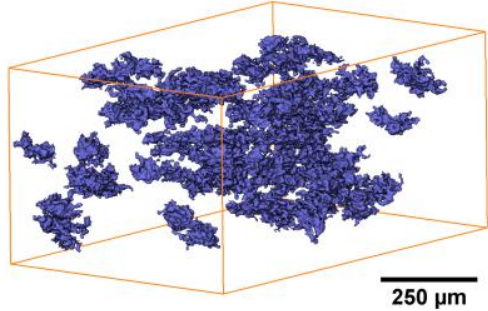

(f)

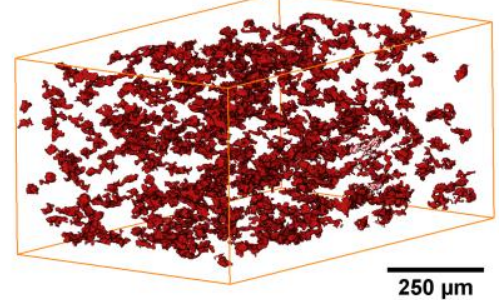

(d)

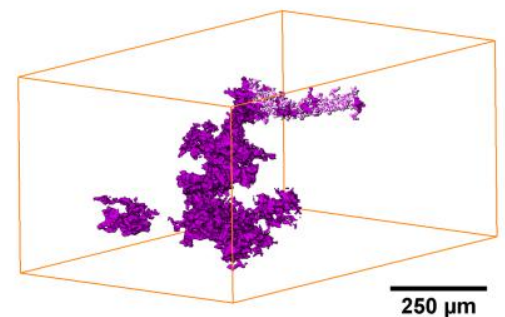

(g)

This article is protected by copyright. All rights reserved. 
(a)

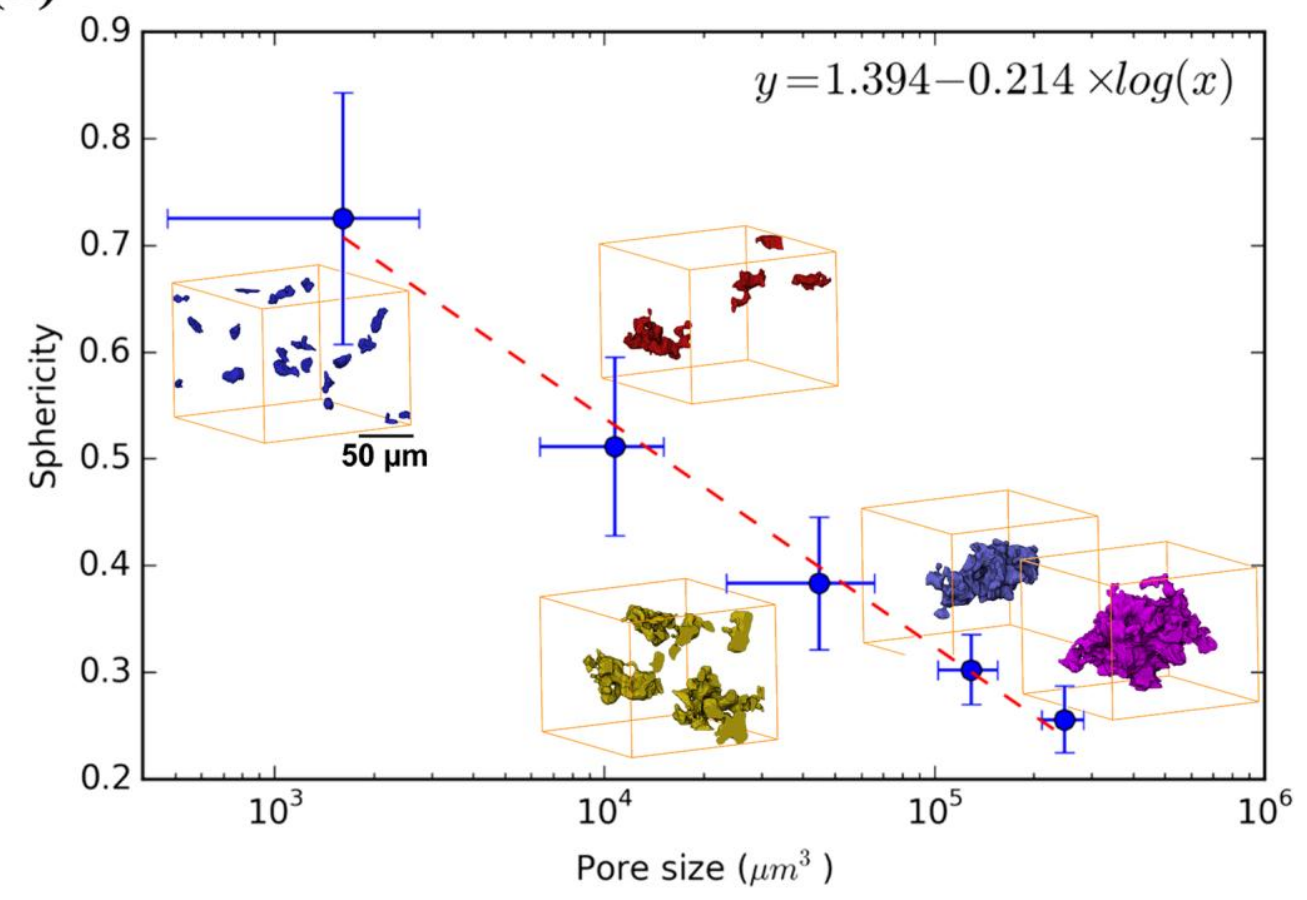

(b)

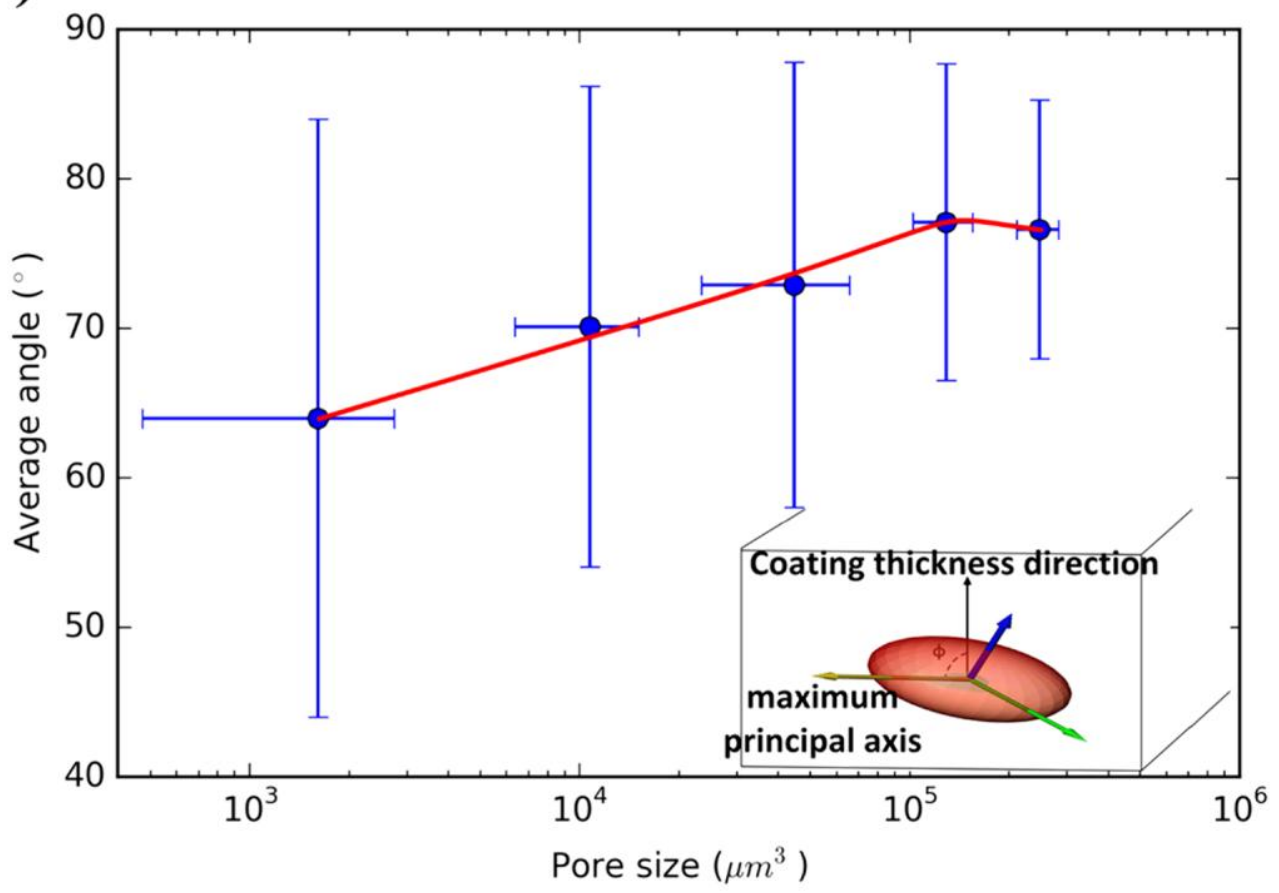

This article is protected by copyright. All rights reserved. 


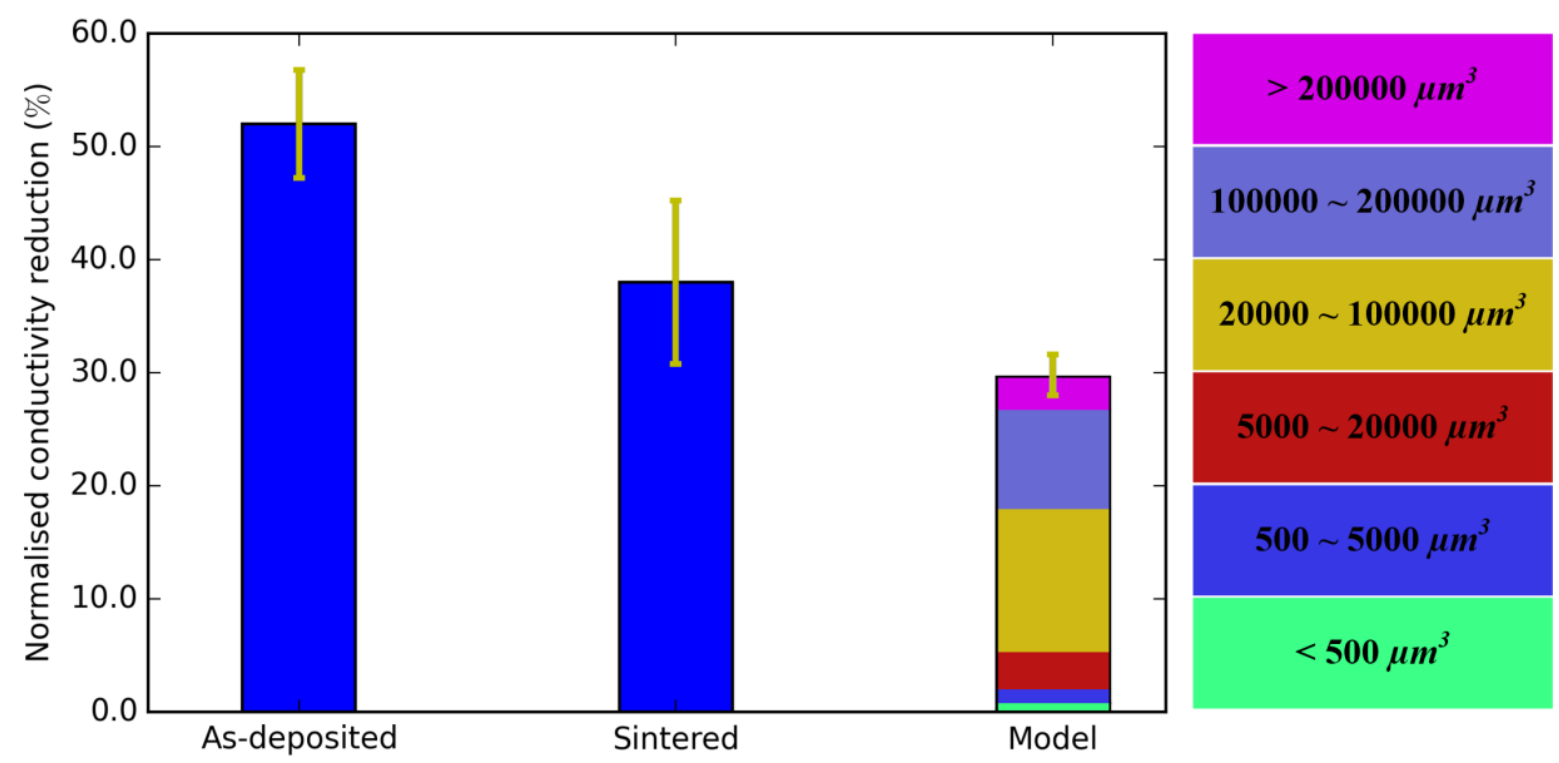

This article is protected by copyright. All rights reserved. 


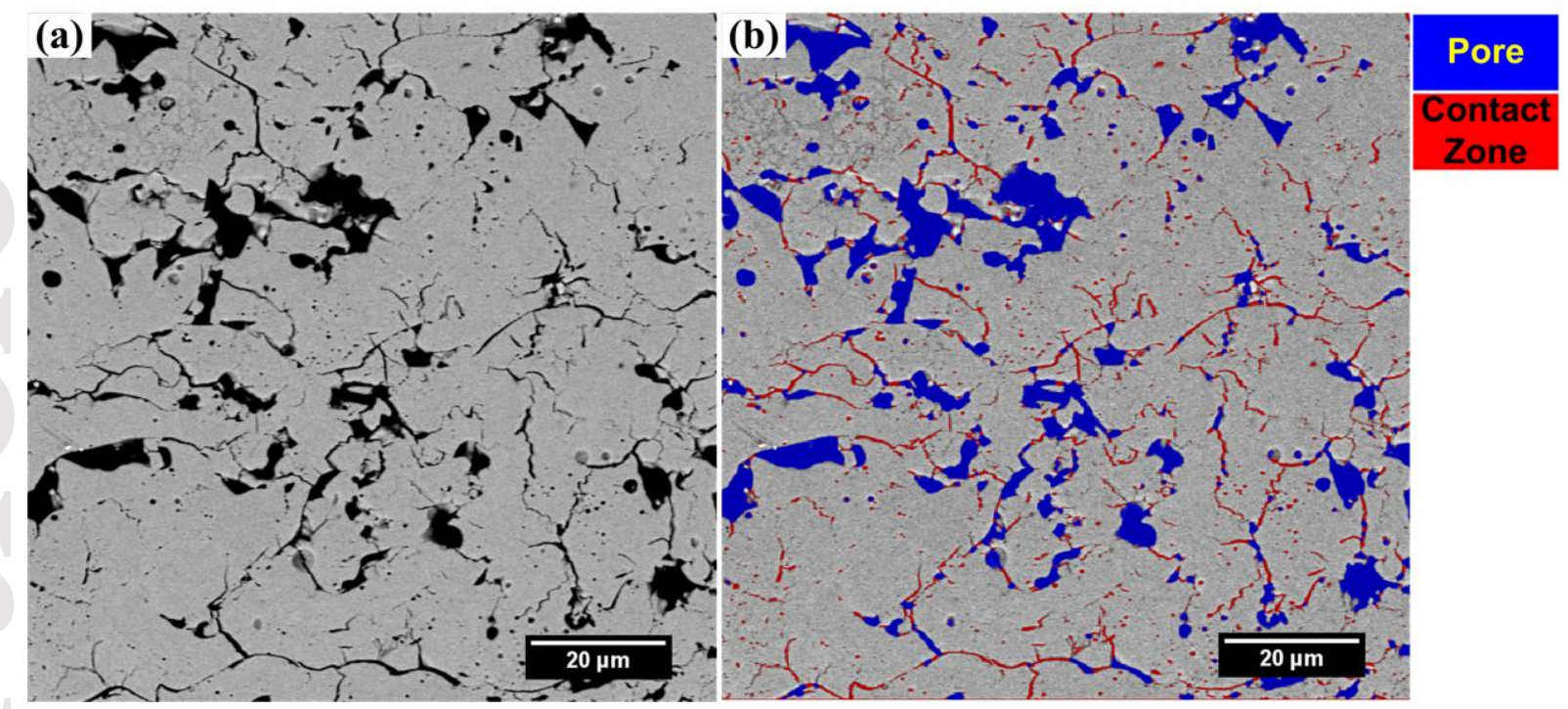

This article is protected by copyright. All rights reserved. 


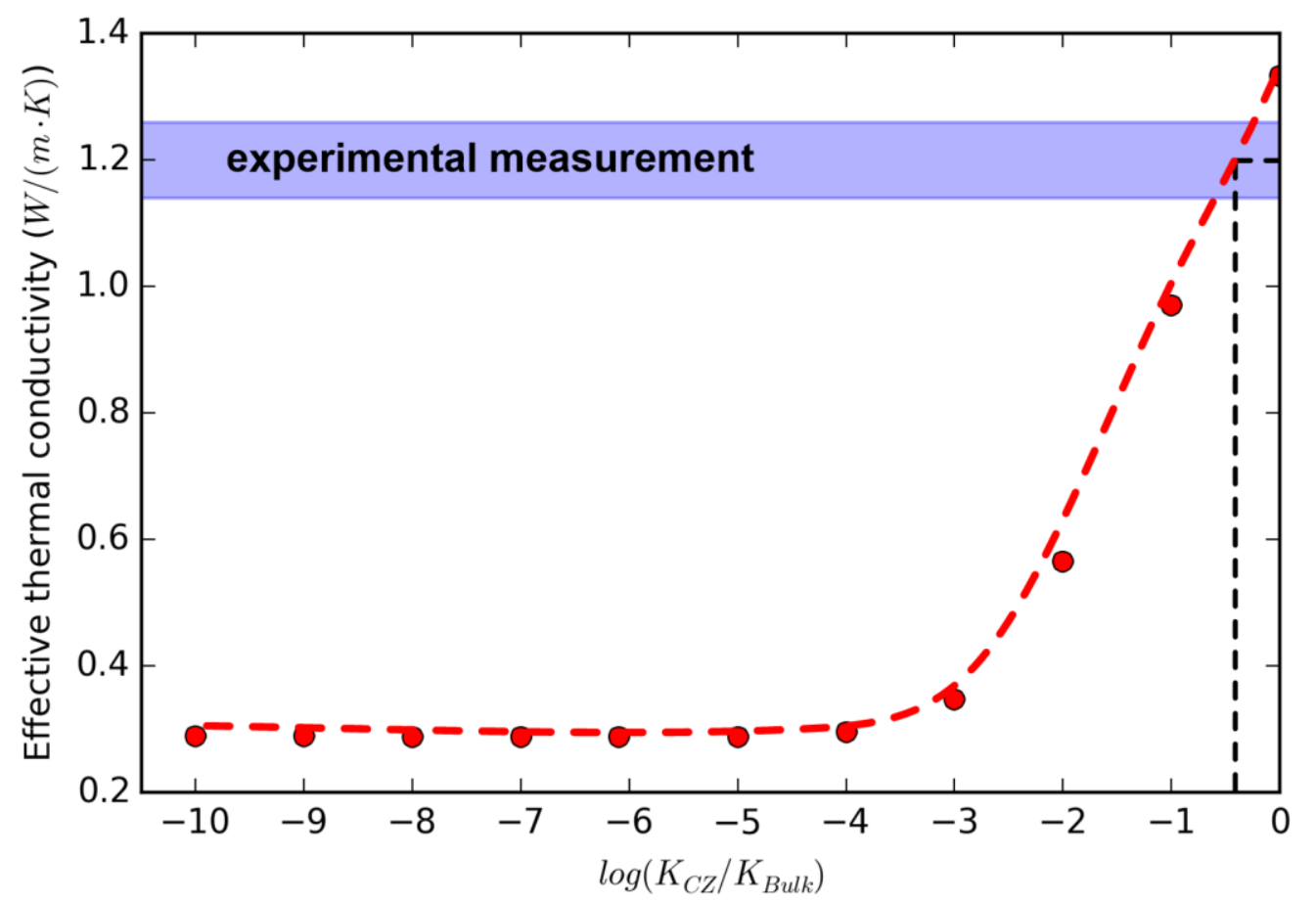

This article is protected by copyright. All rights reserved. 


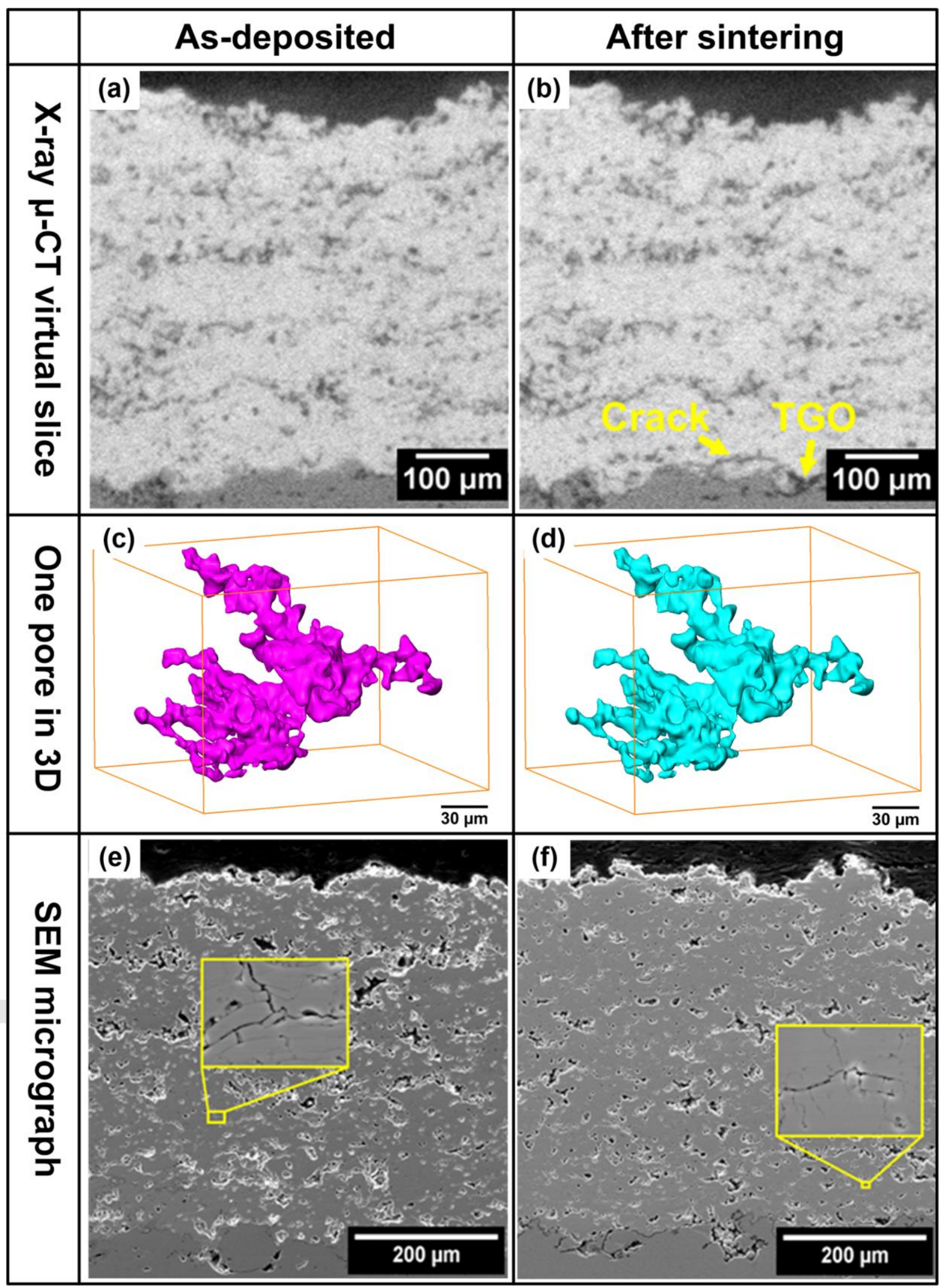

This article is protected by copyright. All rights reserved. 


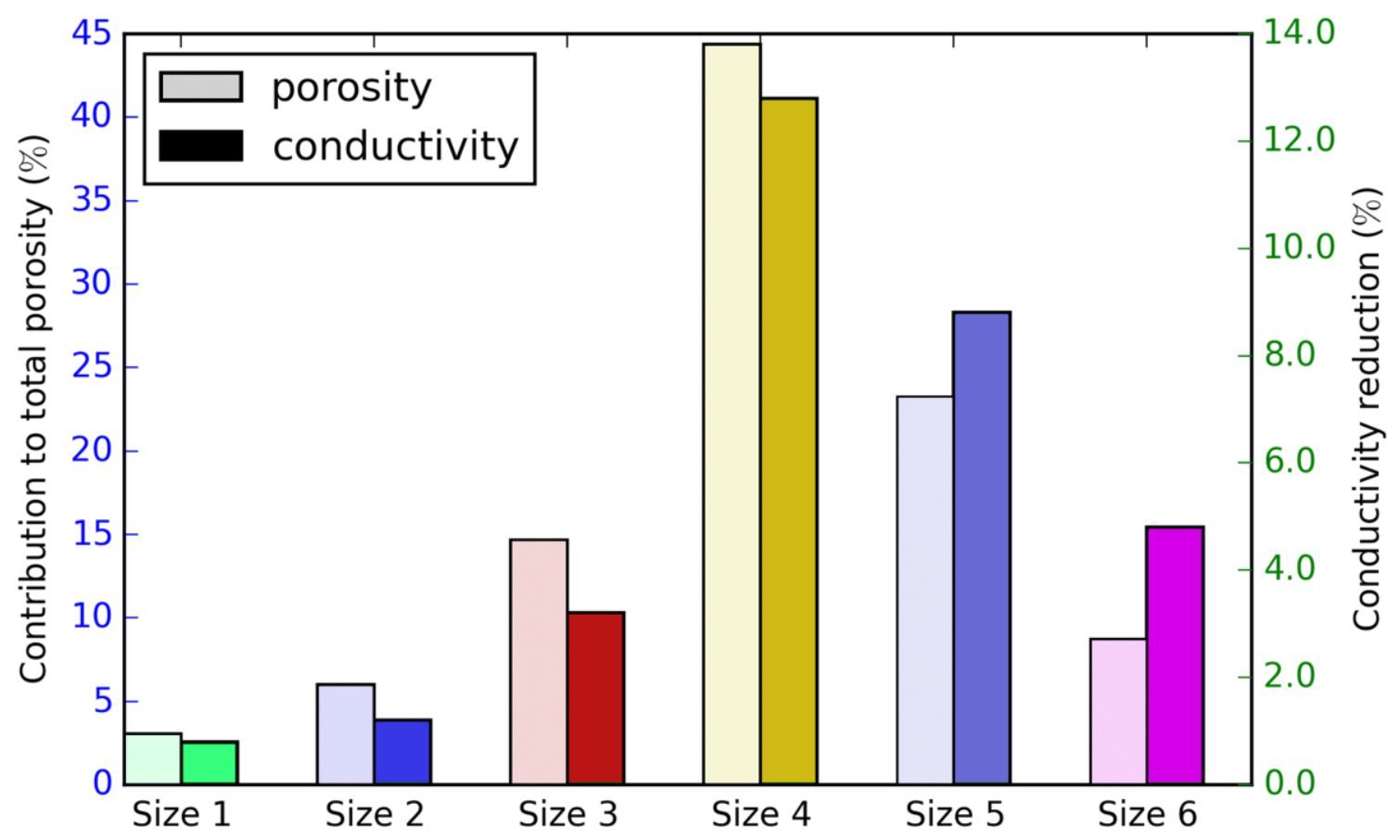

This article is protected by copyright. All rights reserved. 


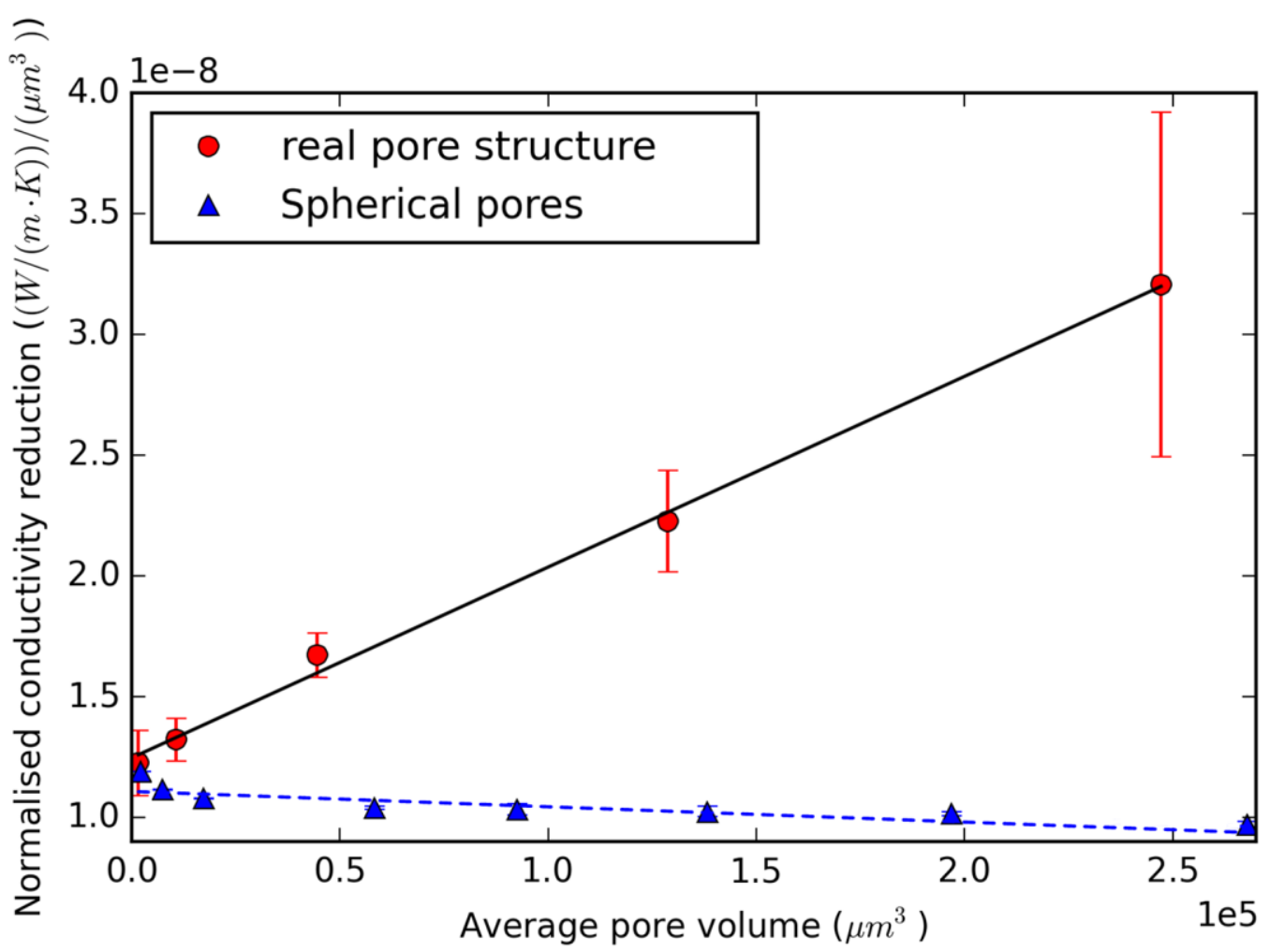

This article is protected by copyright. All rights reserved. 